THE British Government has accepted a recommendation by the Royal Commission on Environmental Pollution that lead should be eliminated from petrol (gasoline). New motor cars will have to be designed for lead-free petrol from the beginning of 1988. In a report on lead pollution published earlier this week (Cmnd 8852, HMSO, $£ 9,20$ ), the Royal Commission argues that no purpose would be served by a further restriction of the lead content of motor spirit below the target of $0.15 \mu \mathrm{g}$ per litre fixed for 1986 .

The commission thus accepts the opinion of the government and of the motor industry that the present target concentration is the lowest at which the performance of internal combustion engines can be enhanced by lead additives.

The commission's report and the government's prompt acceptance of its chief recommendation are nevertheless not the outright "victory" for the anti-lead lobby that has been claimed by organizations such as the Campagin for Lead-Free Air, otherwise known as Clear. Rather, the report is a balanced (and readable) account of lead pollution in the United Kingdom which confirms that for a substantial part of the British population, petrol is not the most important source of lead pollution.

The case for lead-free petrol stems rather from the commission's concern that the average blood-lead concentration in the British population is as much as a quarter of that at which symptoms of "frank poisoning may occasionally occur". The commission says that the narrowness of thsi safety margin is "disturbing", and that there is good reason to reduce the exposure of the general population to lead. Leadfree motor spirit offers the quickest and most certain route to that goal.

The Royal Commission on Environmental Pollution, set up in 1970, independent of the government, and constitutionally is only advisory. The proposals on lead are, however, something of an embarrassment for the government, whose own commissioned report on lead, published in 1979, will appear in retrospect to have been somewhat complacent.

Part of the difficulty is that of estimating the exposure of individuals to lead because of the way in which exceptional environmental circumstances can enormously increase people's intake. Thus it is estimated that the consumption of lead in tapwater can vary from $8.5 \mu \mathrm{g}$ a day to roughly 30 times as much $(255 \mu \mathrm{g}$ a day) where plumbing systems are made of lead and the water is such as to assist its solution. By comparison, in a number of representative and extreme models for lead intake included in the report, the highest adult intake of lead from petrol amounts to $17 \mu \mathrm{g}$ a day.

For adults, dietary intake accounts for an estimated $100 \mu \mathrm{g}$ a day (with the solder on tin cans accounting for 15 per cent of that). The commission draws attention to the increased intake of lead by cigarette smokers, presumably because of the use of lead-based pesticides on tobacco plantations, as well as by those who drink alcohol.

Children are special cases. In the commission's argument, the chief extra source of lead exposure is the intake by children of lead-bearing dust and soil, which may account for as much as $70 \mu \mathrm{g}$ a day in rural areas and $105 \mu \mathrm{g}$ a day in extreme city environments. One of the few gaps in an otherwise persuasive document is the perhaps inevitable lack of data on the ingestion of lead in dust by adults as well as children.

Blood-lead data are sparse, but sufficient to sustain the commission's case that concentrations are uncomfortably high. Surveys carried out among small population groups in different parts of the United Kingdom confirm that concentrations are highest among young children (2-3 years) and decrease with age. Surveys carried out to satisfy a requirement of the European Community in 1979 and 1981 found average adult blood-lead concentrations of $12.8 \mu \mathrm{g} \mathrm{dl}^{-1}$ and $11.0 \mu \mathrm{g} \mathrm{dl}^{-1}$ in inner cities and suburbs respectively.

On the question whether lead pollution can be shown to have caused behavioural changes (principally IQ deficits) in young children, the commission is agnostic. It says that on present evidence for the relationship between blood-lead and IQ, there is no way of telling whether the relationship is causal or indirect, with both variables dependent on a third, such as social class (see also Nature 14 April, p.561).

One of the curious features of the policy now recommended is that the British Government is bound by a European Community directive that requires that the lead concentration in petrol should not be less than $0.15 \mathrm{~g} \mathrm{l}^{-1}$. the government's acceptance of the proposal will require that it should urge stricter environmental standards on its European partners.

\title{
How much will it all cost?
}

THE Royal Commission's report on lead pollution includes an interesting calculation of the economic cost of different ways of reducing petrol-borne lead contamination. (For those who need it, there is also a clear account of the difference between diesel and petrol-driven engines, and of the causes of engine knock.)

Following earlier studies, the commission has considered several different policies for reducing petrol-borne lead, including one in which lead would be removed from vehicle exhausts by means of filters. The commission accepts the relative costs calculated by the government's 1979 working party (but supposes that their absolute value will roughly have doubled).

On this basis, the net present value of the total costs over twenty years of keeping $0.4 \mathrm{~g}$ of lead per litre of petrol but fitting cars with filters is roughly half the cost of switching to lead-free petrol, while annual costs thereafter would be more than halved.

The report describes research carried out in the past few years at the Atomic Energy Research Establishment at Harwell in the past few years which has demonstrated that filters could be fitted physically within existing exhaust systems, and should remove three-quarters of the lead in exhaust gases. Nevertheless the commission comes down against this option on the grounds that filters would be less efficient when in service than when new, and that only lead-free petrol can give a speedy reduction of pollution from petrol-borne lead.

There is, however, very little to choose in cost between unleaded petrol and the policy now decided for 1986, although after a period of twenty years the annual costs of operating the new policy will be more than twice as great (while decreased fuel efficiency in engines with lower compression ratios will increase British fuel consumption by the equivalent of 1.15 million tonnes of crude oil a year).

Part of the commission's argument is that in these circumstances, the incentive for the development of new kinds of internal combustion engines is strong. It asks that the government should encourage the use of diesel engines in smaller vehicles as well as research and development directed towards solutions of the knocking problem.

The most interesting part of the Royal Commission's report is thus the appendix in which it reprints a document supplied by Atlantic Research Associates, an otherwise unidentified organization, in which the relative merits of different kinds of internal combustion engines are compared. The phenomenon of knock in petrol-driven engines occurs at places in the cylinder to which combustion has not had time to travel, but where high octane fuel can be made, so to speak, "to diesel".

More efficient combustion chambers might function without knocking even if the fuel were merely more sensibly distributed, or if the pattern of combustion in the cylinder were more self-consciously designed. The notation that a rough cut of crude oil might fuel suitably designed engines may be an even great challenge. 